\title{
Paixões aristotélicas e tomistas: uma trajetória ao caminho excelente
}

\author{
Éber José dos Santos \\ Joelma Batista dos Santos Ribeiro
}

$\mathrm{O}$ s estudos sobre as paixões têm suas raízes na retórica, especificamente, no livro II de Arte Retórica de Aristóteles (384 - 322 a.C.). O filósofo grego conceitua as paixões como "as causas que introduzem mudanças em nossos juízos, e que são seguidas de pena e de prazer". ${ }^{1}$ Considerado o doutor da Igreja, São Tomás de Aquino (1224-1274) desenvolveu os seus estudos no período da escolástica e marcou a história do pensamento, alicerçado no arcabouço das ideias do filósofo de Estagira. Assim afirma: "A paixão é um efeito do agente no paciente. Ora, o agente natural produz um duplo efeito no paciente: primeiramente, dá-lhe uma forma; em seguida, dá o movimento consequente à forma". Vemos aqui a possibilidade de estabelecermos correlações entre as teorias - e é isso que pretendemos ao longo deste percurso - visto que, ao aproximarmos os pressupostos tomistas das paixões para a retórica, fica evidenciada a influência do orador sobre o auditório.

Na parte II da sua obra Suma Teológica, São Tomás realiza uma abordagem profunda das paixões que ocupa 150 artigos das 27 questões. Para o Doutor Angélico, as paixões poderiam ser obstáculos para o homem atingir seu fim, a bem-aventurança. Por isso, orienta que elas devem ser submetidas à razão para que possam ser usadas apenas em favor do bem e reforço dos atos virtuosos.

As perspectivas aristotélica e tomista das paixões, adotadas neste estudo, encaram-nas como capazes de fazer mudar juízos ${ }^{3}$ e, ainda, de intensificar atos virtuosos, se conduzidas para o bem. ${ }^{4}$ Nesse sentido, as paixões são persuasivas,

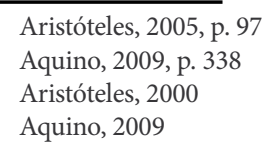


uma vez que têm potencial de fazer o sujeito mudar suas ações, atitudes, ou, pelo menos, levá-lo a uma disposição para isso.

É, portanto, sob o viés retórico que dedicamos este capítulo à investigação das paixões suscitadas no discurso paulino de 1 Coríntios 13 - Hino à caridade - que se encontra na Bíblia Sagrada. Assim, partimos de duas questões de pesquisa norteadoras: Quais a paixões presentes em tal discurso? O amor é a paixão predominante? Para responder a essas inquietações, apresentamos neste trabalho a concepção e a categorização das paixões para Aquino (2009) e Aristóteles (2005); contextualizamos o orador - Paulo -, o auditório, os fiéis da comunidade de fé da cidade de Corinto e, ainda, as circunstâncias em que a epístola de 1 Coríntios foi escrita, principalmente, os capítulos que antecedem e os que sucedem ao corpus selecionado. Finalizamos a análise retórica com ênfase nas paixões provocadas no auditório.

Ressaltamos que nos pautamos teoricamente na obra Arte Retórica (2005) de Aristóteles, principalmente, na segunda parte que o filósofo dedica às paixões, e na parte II da Suma Teológica (2009) de Tomás de Aquino, denominada Paixões da Alma.

\section{Um diálogo entre a paixão tomista e a paixão aristotélica}

Tomás de Aquino compreende a paixão como padecimento em três acepções: a) em sentido geral, pressupõe que todo receber implica um padecer; b) no sentido próprio, receber alguma coisa leva à exclusão de outra, por exemplo, receber saúde e eliminar a doença; c) no sentido contrário, quando se recebe o mal e se perde o bem, como no caso de se receber a doença e ter eliminada a saúde. Esse modo de exclusão, por meio do qual se recebe um bem e elimina-se um mal ou o contrário, é mais apropriado à paixão, segundo Aquino, e vem acompanhado de uma transmutação corporal, pois, para o filósofo, as paixões se encontram no apetite sensitivo que se liga aos órgãos corporais. A título de ilustração, quando somos incitados à vergonha - uma das paixões aristotélicas -, sofremos uma alteração corporal marcada pelo enrubescimento; se iramos por alguma razão, temos um batimento mais acelerado do coração, mudamos a feição etc.

Embora Tomás de Aquino, em Paixões da Alma, Parte II de sua Suma Teológica, não faça menção diretamente ao verbo persuadir, sua afirmação de que "qualquer (...) paixão da alma implica ou movimento ou descanso em relação a alguma coisa", ${ }^{5}$ leva-nos à compreensão de que esse estado de movimento ou

5 Aquino, 2009, p. 349 
repouso, ao qual o filósofo se refere, pode depender da emoção despertada, uma vez que a paixão envolve certo estado de ânimo.

Para o filósofo e doutor da Igreja, todos os atos são gerados a partir de potências que fazem mover a alma e o corpo, as quais podem ser entendidas como aquilo que é determinável ou determinado pelo ato. Os movimentos, pois, para São Tomás, ocorrem quando o agente atua sobre o paciente no sentido de conduzi-lo a uma ação, ou seja, à prática de um ato em direção ao que lhe é colocado.

Tais potências são distinguidas pelo filósofo em: potência vegetativa, que se refere às faculdades de nutrição, crescimento e geração; potência intelectiva, que diz respeito à racionalidade e à vontade; e potência sensitiva, que abrange a faculdade cognoscitiva, os sentidos internos e externos do ser humano e a parte apetitiva, lugar onde se encontram as paixões da alma. ${ }^{6}$

Compreendemos melhor o lugar das paixões no pensamento tomista, quando buscamos etimologicamente que apetite vem do latim appetitus, derivado de ad-petere, ou seja, appetere aliquid: "ter uma inclinação ou propensão a um fim, a uma direção ou a um objeto, tentar chegar a um lugar qualquer, desejar algo". É sob a perspectiva do apetite que Tomás de Aquino estuda as paixões da alma e as conceitua como todo o movimento do apetite provocado pela percepção de algum objeto que inclui uma alteração, uma modificação do sujeito.

Assim, acrescemos que as paixões são explicadas por Aquino (2009) como atos afetivos-sensitivos que levam o sujeito a se mover ao encontro das coisas, apetecendo-as como são em si mesmas. No discurso retórico, dizemos que essa movimentação se dá quando o auditório se move no sentido de aderir à tese a ele apresentada, após ter sido persuadido e estar sob efeito de determinado estado de espírito.

Vale mencionar ainda, que, na concepção de-Tomás de Aquino, a paixão é vista como aquilo que o sujeito, composto de corpo e alma, recebe do mundo exterior. Essa recepção implica um padecer que, consequentemente, causa uma transmutação corporal. Na visão tomista, "a paixão propriamente dita não possa convir à alma senão acidentalmente, quer dizer, enquanto o corpo humano sofre". ${ }^{8}$ Temos aqui mais uma constatação tomista que dialoga diretamente com o discurso retórico. Podemos entender "aquilo que o sujeito recebe do mundo exterior" como o discurso que o auditório recebe do orador e suscita emoções.

A partir do entendimento das paixões em Tomás de Aquino, é mister lembrar que o teólogo categoriza onze paixões e as divide em dois tipos de potências: a potência concupiscível, que tem como objeto o bem ou mal sensíveis e absolutos,

Aquino, 2009

Costa e Silva, 2011, p. 226

Ibid , 2009, p. 304 
inclui o amor, o desejo, a alegria, o ódio, a aversão e a tristeza; e a potência irascível, que contempla o bem ou mal enquanto árduos, difíceis de serem alcançados ou evitados, que abrange a esperança, o desespero, a segurança, o temor e a ira. ${ }^{9}$

Para melhor compreensão dessa categorização e descrição de cada paixão, tomamos por base um quadro elaborado por Costa e Silva (2011) no artigo Breve introdução ao estudo das paixões em S. Tomás de Aquino (II), conforme segue:

Quadro 1: As paixões em Tomás de Aquino

\begin{tabular}{|c|c|c|c|}
\hline Potência sensitiva & Paixão em Aquino & Descrição da paixão & $\begin{array}{l}\text { Objeto } \\
\text { Bem } \\
\text { (simplesmente } \\
\text { considerado) }\end{array}$ \\
\hline \multirow{5}{*}{ Concupiscível } & Amor & $\begin{array}{l}\text { Apreensão de um bem } \\
\text { presente (inclinação conatural } \\
\text { ao bem) } \\
\text { Movimento voltado a um bem } \\
\text { enquanto futuro }\end{array}$ & \multirow[t]{2}{*}{$\begin{array}{l}\text { Bem } \\
\text { (simplesmente } \\
\text { considerado) }\end{array}$} \\
\hline & Alegria (gáudio) & $\begin{array}{l}\text { Fruição do bem presente, ou } \\
\text { seja, a sua posse }\end{array}$ & \\
\hline & Ódio & $\begin{array}{l}\text { Apreensão de um mal presente } \\
\text { (movimento conatural de } \\
\text { repulsa) }\end{array}$ & \multirow{3}{*}{$\begin{array}{l}\text { Mal } \\
\text { (simplesmente } \\
\text { considerado) }\end{array}$} \\
\hline & Fuga ou aversão & $\begin{array}{l}\text { Movimento de distanciamento } \\
\text { de um mal futuro }\end{array}$ & \\
\hline & Tristeza & $\begin{array}{l}\text { O mal (não árduo) já se } \\
\text { encontra no sujeito }\end{array}$ & \\
\hline \multirow{5}{*}{ Irascível } & Esperança & $\begin{array}{l}\text { O bem ausente (futuro) é de } \\
\text { possível alcance }\end{array}$ & \multirow{2}{*}{$\begin{array}{l}\text { Bem árduo } \\
\text { (de difícil } \\
\text { consecução) }\end{array}$} \\
\hline & Desespero & $\begin{array}{l}\text { O mal ausente (futuro) é de } \\
\text { impossível alcance }\end{array}$ & \\
\hline & Audácia & $\begin{array}{l}\text { O mal presente (futuro) se } \\
\text { demonstra superável }\end{array}$ & \multirow{3}{*}{$\begin{array}{l}\text { Mal árduo } \\
\text { (difícil de ser } \\
\text { repelido) }\end{array}$} \\
\hline & Temor & $\begin{array}{l}\text { O mal ausente (futuro) se } \\
\text { demonstra insuperável }\end{array}$ & \\
\hline & Ira & $\begin{array}{l}\text { O mal (árduo) já se encontra } \\
\text { no sujeito }\end{array}$ & \\
\hline
\end{tabular}

Fonte: Os autores [adaptado de Costa e Silva (2011, p. 244)] 
Observamos que nas paixões do concupiscível a contrariedade se dá pelo objeto bem e mal e nas do irascível de igual forma, mas também por afastamento e aproximação. Assim, o contrário de esperança é o temor, a partir do bem e do mal; já quanto à aproximação e afastamento, seu contrário é a audácia. ${ }^{10}$

Por sua vez, Aristóteles, no seu tratado Arte Retórica, apresenta quatorze paixões em pares: cólera e calma; amor e ódio; temor e confiança; emulação e desprezo; vergonha e impudência; além do favor, compaixão, indignação e inveja. O filósofo discorre sobre as paixões a partir das disposições de ânimos que as causam, contra quem se dirigem e os motivos que as levam a serem suscitadas.

Conveniente anotar que, para Tomás Aquino, a única paixão que não tem oposição por contrariedade é a ira, por ser causada por um mal difícil, portanto, ao mencionar que a teoria aristotélica apresenta uma oposição a essa emoção, no caso, a calma, esta se dá por negação ou privação e não por contrariedade, afirma o Doutor Angélico.

Se por um lado a perspectiva aristotélica do estudo das paixões contempla os efeitos persuasivos que as paixões desencadeadas pelo orador causam no auditório, por outro, São Tomás, no contexto cristão do século XIII, está preocupado em tratar como as paixões podem ser obstáculos para o homem atingir seu fim bem-aventurado, uma vez que são os atos afetivos-sensitivos que levam às virtudes ou aos vícios.

Nas duas abordagens, as paixões reverberam-se em estados de ânimos no sujeito que são causados por fatores ou influências externas. Na dinâmica do discurso, as paixões são inculcadas no auditório pelo orador para fazer mudar seus juízos a favor da tese proposta.

Ao pensarmos as paixões na perspectiva tomista, sob o viés do discurso retórico aristotélico, podemos compreender que a divisão das paixões feita por Tomás de Aquino (mal árduo, bem árduo, ou ainda, bem simplesmente considerado, mal simplesmente considerado) indica o grau de empenho que o orador empreenderá para incitar determinadas paixões no auditório, por meio do discurso, pois algumas podem ser mais difíceis e outras mais fáceis.

Nesse sentido, se o orador pretende provocar no auditório o bem ou a comunhão por meio do amor, por exemplo, empreenderá menos esforço no processo de argumentação. Porém, se busca transformar um sentimento de temor em uma emoção positiva, terá de esforçar-se mais, valer-se de estratégias mais contundentes para conseguir seu intento, uma vez que tal paixão, conforme entende o Doutor Angélico, é difícil de ser alcançada, assim como é dificultosa de ser repelida depois de instauradas. 


\section{Os carismas e a resposta do caminho excelente: $o$ orador e o auditório}

O capítulo 13 da epístola de 1 Coríntios, chamado na tradução da Bíblia de Jerusalém de Hino à caridade, intercala o discurso de advertência paulina sobre o uso dos dons espirituais pela comunidade de fé da cidade de Corinto. A construção poética do apóstolo apresenta-se como uma digressão que endossa o alto teor persuasivo do discurso paulino que mobiliza aspectos afetivos, passionais e racionais para levar o auditório à ação, no caso, à atitude adequada no uso dos dons espirituais.

Os aspectos afetivos da persuasão se estabelecem pela via do ethos, a imagem que o orador, Paulo, imprime no auditório por meio do discurso; os racionais se dão pelo discurso, o logos, naquilo que demonstra ou parece demonstrar ${ }^{11}$ no uso dos raciocínios e das figuras. Já os aspectos passionais, por sua vez, se encontram no pathos, nas disposições, paixões suscitadas no auditório, os fiéis de Corinto. É nesse aspecto da persuasão retórica, o patético, que nos debruçamos ao analisar o corpus paulino selecionado.

Paulo, também conhecido como o apóstolo dos gentios, é responsável pela expansão do cristianismo no século I d.C. Apesar de não ter, como os primeiros discípulos, encontrado fisicamente Cristo, é após uma experiência transcendente no caminho para cidade de Damasco, que passa a viajar para diferentes lugares, com a finalidade de divulgar a nova fé e fundar igrejas.

Em 50 d.C., chega à cidade de Corinto, hospeda-se com o casal Priscila e Áquila e põe em prática o ofício de fabricar tendas para sustentar-se. Utilizase do seu trabalho e das visitas à sinagoga para ter acesso às pessoas e, assim, angariar novos adeptos à fé. No período de dezoito meses que permanece na cidade, instrui a jovem comunidade sobre os princípios e a doutrina cristã, além de motivá-la a conquistar outros fiéis. ${ }^{12}$ Paulo teria escolhido fundar uma igreja em Corinto tendo em vista seu potencial de disseminar o evangelho, ${ }^{13}$ uma vez que, por ser portuária, os conversos poderiam levar, mais facilmente, para outras regiões a fé em Cristo.

Havia na cidade de Corinto um grande templo da deusa Afrodite, que tinha as prostitutas culturais, com as quais muitos capitães gastavam todo seu dinheiro entretendo-se. Também se cultuavam vários deuses gregos como Ártemis, Dionísio, Hélio, Hermes, Apolo, Zeus, Isis, Eros e outros, os quais possuíam

11 Aristóteles, 2005

12 Comblin, 1991

13 Murphy-O'connor, 2004 
lugares de cultos. ${ }^{14}$ Essas influências pagãs interferiram no comportamento da jovem igreja cristã de Corinto, que valorizava, devido as suas raízes religiosas, atributos sobrenaturais, como os dos deuses gregos. Provavelmente, por isso, buscavam sobremaneira os dons espirituais e encarava-os como uma forma de poder sobre os outros e exaltação de si.

Paulo, em 1 Coríntios 1,26, comenta sobre a composição da comunidade: “(...) não há entre vós muitos sábios segundo a carne, nem muitos poderosos, nem muitos de família prestigiosa”. Podemos entender que os sábios são os instruídos; os poderosos, os influentes que tinham peso na vida cívica; e os de família prestigiosa, aqueles nascidos na aristocracia. ${ }^{15}$

Observamos, assim, que a comunidade de Corinto era composta por pessoas de diferentes classes sociais, influências políticas, formação religiosa, instrução e recursos financeiros, tendo em comum apenas o cristianismo. Essas diferenças criaram dentro da comunidade um espírito competitivo e faccioso que, além de culminar em vários problemas de ordem doutrinária, refletiram no exercício caridoso e benevolente de suas habilidades e dons espirituais no serviço ao próximo.

A epístola de 1 Coríntios surgiu a partir das informações que Paulo obteve dos coríntios, quando estava em Éfeso, após três anos de sua partida. Os familiares de Cloé (1 Co 1,11), ao regressarem das negociações realizadas em Corinto, informaram o apóstolo que a comunidade apresentava problemas como: casamento incestuoso, homossexuais que presidiam a liturgia, embriaguez na Eucaristia, além do partidarismo.

Assim, após confirmar tais informações e com o intuito de esclarecer as dúvidas dos fiéis e, ainda, advertir sobre aspectos de suas vidas que considerava problemáticos à fé cristã, Paulo redigiu a carta canônica de 1 Coríntios, cujos temas versavam sobre a impureza sexual, os alimentos oferecidos aos ídolos, a ceia do Senhor, o partidarismo existente na comunidade, inclusive, faz referências a um grupo que se considerava mais espiritual do que os demais.

Paulo dedica três capítulos dos dezesseis da carta de 1 Coríntios à questão dos dons espirituais, pois algumas pessoas exerciam os dons espirituais para autopromoção dentro da comunidade. Em razão dessa supervalorização dos dons, é que o apóstolo se empenha a instrui-los sobre os dons espirituais e, acentua, no capítulo 13, "O caminho excelente" (1Co 12,31), a virtude para exercê-los.

No capítulo 12, que antecede o Hino à caridade, o apóstolo reforça que há diversidade de dons ou carismas (1Co 12,4) e que são para serem usados para 
o benefício de todos (1Co 12,7), tais como a sabedoria, a ciência, a fé, a cura, o milagre, a profecia, o discernimento dos espíritos, o dom de falar em línguas e o da sua interpretação.

Ainda, para instruir sobre a importância da união de todos os fiéis com seus diferentes dons na comunidade, utiliza um apólogo do corpo humano. Nele, compara as conexões das partes do corpo humano, seus membros, a cada pessoa da comunidade que precisa cumprir sua função, usar seu dom, para o bom funcionamento de todo o corpo.

Também descreve uma ordem hierárquica na Igreja que contempla alguns dos dons: “...Vêm, a seguir, os dons dos milagres, das curas, da assistência, do governo e o de falar em línguas" (1Co 12,27-28). A abordagem paulina sobre os dons revela a maneira como aquela comunidade encarava e exercia os dons espirituais. Os fiéis com os dons mais visíveis, provavelmente, tinham melhores colocações e prestígio dentro da comunidade, além de ocupar posição de liderança.

O capítulo 14, posterior ao Hino à caridade, trata da superioridade do dom da profecia em detrimento ao de línguas, uma vez que a profecia, segundo Paulo, edifica toda a assembleia e o de línguas apenas aquele que fala. Também orienta sobre a manifestação do dom de línguas no culto público e recomenda que fale um de cada vez e com intérprete (1Co 14) para que não ocorra confusão.

Paulo é muito enfático ao recomendar que os crentes de Corinto desejem os dons espirituais: "Aspirai aos dons mais altos. Aliás, passo a indicar-vos um caminho que ultrapassa a todos" (1Co 12,31). No entanto, dedica o capítulo 13 para persuadi-los de como devem exercer seus dons e sob qual motivação.

\section{O caminho excelente: $o$ amor}

O capítulo 13 de 1 Coríntios consiste em uma digressão, em forma poética, um hino que exalta a caridade. É importante ressaltar que no texto grego, língua em que foi originalmente escrito o Novo Testamento, o termo utilizado por caridade é agape, agapao na forma verbal, que significa receber ou tratar com amor: amar, querer, preferir, estar contente ou satisfeito. ${ }^{16}$ Bordelois ainda afirma que:

É o amor que se dá sem olhar outra condição a não ser a do ser humano

próximo. Como indica Roxane Kreimer, o ágape cristão difere do Eros ou da philia dos gregos, na qual é o apetite de um homem superior que nasce da necessidade de ser feliz, mas sim uma dádiva de vida, que

16 Bordelois, 2007 
Paixões aristotélicas e tomistas: uma

trajetória ao caminho excelente

pode chegar até a entrega de si mesmo. Não é uma relação binária, mas uma abertura ao universal, que inclui os inimigos. ${ }^{17}$

O discurso laudatório de Paulo, em 1 Coríntios 13, exalta o tipo de amor que não espera correspondência, reconhecimento ou lucro, apenas o bem-estar do outro. $\mathrm{O}$ agape ${ }^{18}$ é uma dádiva a ser conquistada, um "caminho excelente" que capacita o amante a entregar-se em favor não só do ser amado, mas de qualquer ser, até o inimigo, sem sequer pensar em reciprocidade ou vantagem.

A tradução de agape por caridade no português no texto paulino decorre da influência da tradução latina do texto sagrado realizada por São Jerônimo, a Vulgata, que adota o termo caritas. Morris comenta que "Jerônimo usou esta versão porque sabia da inconveniência do termo latino amor como tradução do grego ágape" ${ }^{19}$ Por isso, a Bíblia de Jerusalém, que utilizamos neste trabalho, faz uso do termo caridade em detrimento ao termo amor na sua tradução.

O discurso paulino analisado carrega a temática do amor (agape) para persuadir os fiéis de Corinto a praticar os dons espirituais, com a atitude proposta por esse tipo de amor que mobiliza paixões, as quais alteram os estados de ânimo, os juízos ${ }^{20}$ e, consequentemente, levam às mudanças de atitudes e ações ou, pelo menos, à disposição para tal.

Nos três primeiros versículos do Hino à caridade, Paulo utiliza a figura de presença com a repetição de "Ainda que (...)". As repetições são completadas com cada um dos dons mencionados no capítulo anterior: línguas, profecia, mistério, ciência, fé e assistência (1Co 12,8-12). A forma condicional dos verbos cria a expectativa da consequência do uso do dom que é frustrada pela negativa recorrente em cada estrofe "se não tivesse caridade". Vejamos:
Ainda que eu falasse línguas, as dos homens e as dos anjos, se eu não tivesse a caridade, seria como bronze que soa ou como címbalo que tine.

Ainda que tivesse o dom da profecia, o conhecimento de todos os mistérios e de toda a ciência,

17 Bordelois, 2007, p. 84, grifo nosso

18 Agape, utilizado no texto na forma itálica e sem acento, remete ao sentido grego do termo.

19 Morris, 1986, p. 145

20 Aristóteles, 2005 
ainda que eu tivesse toda a fé,

a ponto de transportar montanhas,

se não tivesse a caridade,

nada seria.

Ainda que distribuísse
todos os meus bens aos famintos,
ainda que entregasse
meu corpo às chamas,
se não tivesse a caridade,
isso nada me adiantaria (1Co 13,1-3).

A sequência das três estrofes forma uma amplificação que enfatiza o resultado inútil da utilização dos dons sem a caridade. $\mathrm{O}$ tom patético é intensificado com os empregos dos dons descritos hiperbolicamente: "línguas, as dos homens e as dos anjos"; "conhecimento de todos os mistérios e de toda a ciência"; "a fé, a ponto de transportar montanhas"; "entregar meu corpo às chamas". O auditório é levado a perceber que mesmo os dons exercidos exageradamente podem não ser suficientes, caso não se apresentarem com a virtude da caridade.

Mais do que levar o auditório a exercer seus dons, Paulo, por meio do discurso, pretende suscitar no auditório o desejo de exercê-los despretensiosamente. $\mathrm{Na}$ perspectiva tomista, a potência intelectiva move o ser pela vontade, é racional; a potência sensitiva, por sua vez, faz mover-se pelo apetite, são as paixões da alma. São essas últimas que o apóstolo, o orador, inculca no auditório.

A amplificação insufla no auditório a paixão do favor. Segundo Aristóteles, o favor consiste no "serviço pelo qual, diz-se, aquele que possui concede ao que tem necessidade, não em troca de alguma coisa, nem com o fim de obter alguma coisa, nem com o fim de obter alguma vantagem pessoal, mas no interesse do favorecido". ${ }^{21}$

Vidal, nos seus estudos sobre a paixão do favor, comenta que ela "não é uma emoção se não uma ação cuja função é ser causa da philia e obstáculo da ira" ${ }^{22}$ A concepção do estudioso sobre a paixão do favor como causadora da amizade (philia) remonta a concepção aristotélica de amor (amizade). Para o estagirita, amar "é querer para outrem aquilo que reputamos serem bens, e isto não em nosso interesse, mas no interesse dele; é também, na medida das nossas

21 Aristóteles, 2000, p. 49

22 Vidal, 2017, p. 124, tradução nossa - No original: no es una emoción, sino una acción cuya función es ser causa de la philía y obstáculo de la ira 
forças, agir para proporcionar-lhe essas vantagens". ${ }^{23}$ Nesse sentido, podemos entender que, ao incutir a paixão do favor, a paixão do amor é conjuntamente viabilizada por meio do discurso.

Para Tomás de Aquino (2009), o amor pode ser compreendido como paixão quando causa mudança do apetite pelo objeto apetecível, assim, o movimento em direção a esse objeto é o desejo e a sua obtenção é o repouso, a alegria. Aquino afirma que todas as paixões nascem do amor ao bem, que é causa do amor, e tendem à união com o bem desejado. Nesse sentido, o desejo é gerado por um tipo de complacência pelo objeto amado que não deixa de caracterizar certo favor/obsequiosidade. É essa movimentação passional que o discurso trabalha ao suscitar o favor e o amor no auditório para o exercício dos dons.

Nos versículos de 4 a 7, o apóstolo descreve a caridade:

A caridade é paciente,

A caridade é prestativa, não é invejosa, não se ostenta, não se incha de orgulho.

Nada faz de inconveniente, não procura o seu próprio interesse, não se irrita, não guarda rancor.

Não se alegra com a injustiça, mas se regozija com a verdade.

Tudo desculpa, tudo crê, tudo espera, tudo suporta (1Co 13,4-7).

Paulo descreve a caridade, por meio do lugar da qualidade ${ }^{24}$ como uma virtude que é manifestada por intermédio dos atos, o que, para Aquino (2009), são capazes de levar o homem para seu fim bem-aventurado, se praticados.

No entanto, o apóstolo ao descrever a caridade também pelo viés da negação, do que não é, desperta no auditório pesar, tristeza. A tristeza para Aquino "é um mal presente" ${ }^{25}$ que se encontra no sujeito, uma paixão concupiscível fácil de ser

23 Aristóteles, 2000, p. 23

24 Lugares da qualidade para Perelman \& Olbrechts-Tyteca (1996) consistem nos acordos e consensos de valores estabelecidos pelo orador com o auditório a partir do que é raro, durável, insubstituível, original, marginal, anômalo 
sentida e difícil de ser repelida. As negações paulinas "não é invejosa", "não se ostenta", "não se incha de orgulho", "nada faz de inconveniente", "não procura o seu próprio interesse", "não se irrita" e "não guarda rancor" confrontam o comportamento de autopromoção e disputa por posição que a comunidade de Corinto buscava por meio do uso dos dons espirituais apontadas na epístola (1Co 12).

A transitoriedade dos dons e a permanência da caridade acentuam não só a importância dessa virtude, mas intensifica o aspecto passional do discurso:

A caridade jamais passará.

Quanto às profecias, desaparecerão.

Quanto às línguas, cessarão.

Quanto à ciência, também desaparecerá.

Pois o nosso conhecimento é limitado,

e limitada é a nossa profecia (1Co 13, 8.9).

O apóstolo suscita a tristeza no auditório de Corinto, pesar pelas suas atitudes que não revelam a virtude. Mas no versículo 10, iniciado com uma conjunção adversativa, passa a inculcar a esperança no auditório: "Mas, quando vier a perfeição, o que é limitado desaparecerá". A perfeição a que Paulo se refere é a virtude a ser buscada, a caridade que é colocada como uma possibilidade quase certa.

A esperança encontra-se, segundo o Doutor Angélico, na potência do irascível, a qual ocorre quando o bem ausente, projetado para o futuro, é de possível alcance. ${ }^{26}$ Paulo, após investir o auditório de pesar ao confrontar o quão distante suas atitudes têm estado da caridade, injeta, nesse momento, a esperança que é endossada pela ilustração em primeira pessoa:

Quando era criança,
falava como criança,
pensava como criança,
raciocinava como criança.
Depois que me tornei homem,
fiz desaparecer o que era próprio da criança (1Co 13,11). 
Perelman e Olbrechts-Tyteca observam que "a ilustração é muitas vezes escolhida pela repercussão afetiva que pode ter", ${ }^{27}$ uma vez que proporciona o entendimento da tese por meio da assimilação da realidade do auditório. A ilustração paulina impressiona a imaginação do auditório e o sensibiliza, pois compara o comportamento egoísta do uso dos dons pelos coríntios à figura da criança que ainda não apresenta a maturidade de um adulto. $O$ orador estabelece uma empatia com auditório, uma afetividade que contribui para a construção crível do seu ethos.

A esperança de obtenção da caridade continua a ser insuflada no auditório pela ilustração e pela colocação metafórica:

\author{
Agora vemos em espelho \\ e de maneira confusa, \\ mas, depois, veremos face a face. \\ Agora meu conhecimento é limitado, \\ mas, depois, conhecerei como sou conhecido (1Co 13,12).
}

Ressaltamos que a imagem dos espelhos do século I d.C. eram distorcidas, por isso na construção metafórica, ver "face a face", como é colocado pelo orador, é a forma mais nítida, sem mistérios, sem embaraços ao entendimento. Paulo, dessa forma, impregna o auditório de esperança de obtenção da caridade, bem ausente, mas possível, ${ }^{28}$ e encerra o discurso referindo-se ao presente:

Agora, portanto, permanecem fé,

Esperança, caridade,

essas três coisas.

A maior delas, porém, é a caridade (1Co 13,13).

Paulo finda seu discurso laudatório com a exaltação da perenidade e da grandeza da caridade que se sobressai à fé e à esperança. A movimentação passional provocada pelas paixões suscitadas pelo orador - Paulo - contribuem para levar o auditório - os coríntios - à adesão da tese inicial do uso despretensioso dos dons espirituais. 


\section{Considerações finais}

Estabelecemos neste capítulo um movimento que visou a abordar um diálogo entre Aristóteles e o filósofo e teólogo São Tomás de Aquino acerca do pathos, na análise das paixões no discurso paulino do Hino à caridade. Ao decorrer do trabalho, entendemos ter conseguido responder às duas questões norteadoras. Identificamos no discurso paulino as paixões predominantes como: a tristeza, a esperança, o favor, e verificamos que o amor não é a principal paixão que Paulo quis provocar nos coríntios. Na verdade, o amor é o tema do discurso analisado, que é apresentado na tradução bíblica utilizada como caridade.

O apóstolo propõe aos coríntios que busquem o "caminho excelente" para exercerem os dons, ou seja, a caridade/amor (agape). Ademais, consideramos que Paulo, como orador, utiliza eficazmente a movimentação patética na digressão que intercala o seu discurso sobre o uso dos dons. O auditório é, dessa forma, levado a tomar uma atitude, mover-se, no caso, ao uso despretensioso dos dons espirituais.

De início dissemos que, para o pensamento tomista, o agente produz um efeito duplo no paciente, visto que, ao mesmo tempo que lhe dá uma forma, incita-o a um movimento. Ao estabelecermos uma correlação com o discurso de Paulo, podemos inferir que o apóstolo: primeiro, dá forma, apresenta aos coríntios a importância da caridade - esta concebida como o objeto apetecível, ${ }^{29}$ por meio de argumentos que a qualifica, e incute, sobretudo, a tristeza no auditório.

Em seguida, ele incute o movimento que deveriam seguir, a partir das reflexões que traz, pois mostra que podem mudar a forma egoísta da prática dos dons por uma atitude mais condizente ao cristianismo - estabelece-se, então, um movimento em direção ao objeto apetecível, isto é, à prática da caridade. Nesse momento, portanto, é suscitada a paixão da esperança e, assim, o apóstolo mostra-lhes que não estão condenados, antes, têm como reverter a situação, se buscarem o caminho excelente. 


\section{Referências}

AQUINO, T. Suma Teológica. As paixões da alma. Vl. 3. São Paulo: Edições Loyola, 2009. ARISTÓTELES. Arte retórica e arte poética. 17. ed. Tradução de Antônio Pinto de Carvalho. Introdução e notas de Jean Voilquim e Jean Capelle. Rio de Janeiro: Ediouro, 2005.

. Retórica das paixões. Prefácio de Michel Meyer. Tradução de Isis Borges B. da Fonseca. São Paulo: Martins Fontes, 2000.

BÍBLIA DE JERUSALÉM. 4. ed. São Paulo: Paulus, 2006.

BORDELOIS, I. Etimologia das paixões. Tradução Luciano Trigo. Rio de Janeiro: Odisseia Editorial, 2007.

COMBLIN, J. Comentário bíblico: segunda epístola aos Coríntios. Petrópolis: Vozes, 1991.

COSTA e SILVA, J. B. Breve Introdução ao estudo das Paixões em S. Tomás de Aquino (I e II). Sapientia Crucis: Revista Filosófico-Teológica, ISSN 1984-8722, No. 12, 2011, p. 219-250. Disponível em: <https://institutumsapientiae.files.wordpress.com/2011/07/sc-2010-06joc3a3o.pdf> . Acesso em: 4 set. 2020.

MORRIS, L. I Coríntios: Introdução e comentário. Série Cultura Bíblica. Traduzido Odayr Olivetti. São Paulo: Edições Vida Nova, 1986.

MURPHY-O'CONNOR, J. Paulo biografia crítica. Tradução Barbara Theoto Lambert. São Paulo: Loyola, 2004.

PERELMAN, C.; OLBRECHTS-TYTECA, L. Tratado de argumentação: a nova retórica. Tradução Maria Ermantina Galvão. São Paulo: Martins Fontes, 1996.

RIBEIRO, J. B. dos S. A apologia de Paulo na segunda epístola aos Coríntios: uma análise retórica. Orientador Luiz Antonio Ferreira. 2010. 117f. Dissertação (Mestrado em Língua Portuguesa) - Programa de Estudos Pós-graduados em Língua Portuguesa, Pontifícia Universidade Católica de São Paulo, São Paulo, 2010.

VIDAL, G. R. La funcion persuasiva de la kharis en la retórica aristotélica (II 7, 1385A16B11). In: FIGUEIREDO, Maria Flávia; VIDAL, Gerardo Ramirez; FERREIRA, Luiz Antonio (Orgs.). Paixões aristotélicas. Franca, SP: Unifran, 2017.261 p. Disponível em: < https://www.estudosretoricos.com.br/downloads/livros/paixoes-aristotelicas.pdf>. Acesso em: 15 ago. 2020. 
